\title{
DE ORGANIZACIONES A COLECTIVOS JUVENILES PANORAMA DE LA PARTICIPACIÓN POLÍTICA JUVENIL
}

\author{
ÁNGELA GARCÉS MONTOYA*
}

\begin{abstract}
RESUMEN
En el marco de la investigación «Prácticas de participación política juvenil desde las cuales los y las jóvenes construyen ciudadanías en la ciudad de Medellín», el presente artículo se propone reconocer formas de agrupación juvenil que transitan entre las organizaciones y los colectivos juveniles, consideradas dos modalidades divergentes en su participación política. En principio, a la organización juvenil resulta posible nombrarla «forma oficial» de participación social, comunitaria, política y ciudadana de los jóvenes, porque parten del reconocimiento y aceptación de estructuras, objetivos e intereses colectivos y son fundadas por instituciones formales propias del mundo adulto: pastorales juveniles, grupos scout, partidos políticos, grupos rurales. Otras modalidades de participación obedecen a intereses propiamente de los jóvenes; y aquí se destacan los grupos culturales, musicales, estéticos y de resistencia. Entre unos y otros veremos cómo estas formas de agrupación oscilan entre las organizaciones y los colectivos juveniles.
\end{abstract}

PALABRAS CLAVE: PARTICIPACIÓN JUVENIL, AGRUPACIÓN JUVENIL

* Historiadora y Magíster en Estética. Docente e investigadora de la Facultad de Comunicación, Universidad de Medellín, Medellín, Colombia. Correo electrónico: agarces@udem.edu.co. 


\title{
DE ORGANIZAÇÃOES A COLETIVOS JUVENIS PANORAMA DA PARTICIPAÇÃO POLÍTICA JUVENIL
}

\begin{abstract}
RESUMO
No marco da pesquisa «Práticas de participação política juvenil a partir das quais os/as jovens constroem cidadanias na cidade de Medelín», este artigo se propõe a reconhecer as formas de agrupamento juvenil que transitam entre as organizações e os coletivos juvenis, consideradas duas modalidades divergentes de participação política juvenil. Em princípio, é possível definir a organização juvenil como a «forma oficial» de participação social, comunitária, política e cidadã dos jovens, elas partem do reconhecimento e aceitação de estruturas, objetivos e interesses coletivos e são fundadas por instituições formais próprias do mundo adulto, como as pastorais juvenis, grupos de escoteiros, partidos políticos e grupos rurais. Outras formas de participação juvenil partem de interesses propriamente juvenis, destacando-se os grupos culturais, musicais, estéticos e de resistência. Entre uns e outros veremos como as formas de agrupamento juvenil oscilam entre as organizações e os coletivos juvenis.
\end{abstract}

PALAVRAS-CHAVE: PARTICIPAÇÃO JUVENIL, AGRUPAMENTO JUVENIL

\section{A GROUP OF YOUTH ORGANIZATIONS - OVERVIEW OF THE POLITICAL PARTICIPATION OF YOUTH}

\begin{abstract}
As part of the investigation «juvenile political participation practices from which youth build citizenship in the city of Medellín», This article suggests ways to recognize the youth group that travel between organizations and youth groups identified as two divergent forms of political participation of youth. In principle it is possible to name the youth organization as «officially» social participation, community, political and civic youth, they are based on the recognition and acceptance of structures, objectives and collective interests are based on formal institutions own the world adult, such as youth ministry, scout groups, political parties, rural groups. Other forms of youth participation, youth are based on actual interest, this highlights the cultural groups, musical, aesthetic and resistance. Between them we'll see how youth group forms vary between organizations and youth groups.
\end{abstract}

\section{PALABRAS CLAVE: YOUTH PARTICIPATION, YOUTH GROUPS}




\section{INTRODUCCIÓN}

AFIRMAMOS QUE LAS ORGANIZACIONES juveniles tienen su origen y propósitos fuera del universo juvenil y generan vínculos ideológicos y financieros con instituciones de alta trayectoria adulta de perfiles religioso, político o social. Mientras, los colectivos juveniles son impulsados por los propios jóvenes en respuesta a necesidades o desafíos a la autoridad y a las instituciones adultas; estos colectivos encuentran en la cultura y la estética sus nichos de acción política.

Al explorar las dinámicas de participación de los y las jóvenes a través de organizaciones y colectivos se puede reconocer cómo estas experiencias, desarrolladas por jóvenes, giran en torno a propuestas sociales y culturales que muestran una funcionalidad que dista mucho de las dinámicas organizativas estructuradas, porque las organizaciones juveniles parten de la acción que ejerce un grupo sobre sus propios integrantes, definiendo explícitamente sus objetivos, funciones, tareas y formas en que se relacionarán sus integrantes.

En particular, podría decirse que las formas de agrupación juvenil promovidas por el mundo adulto tienden más a constituirse en organizaciones estructuradas con personería jurídica y con intereses y acciones precisas a corto y largo plazo; en contraste, otras formas de agrupación juvenil se caracterizan por intereses sociopolíticos alternativos; es decir, se resisten a la organización jerárquica y adultocéntrica y prefieren el gobierno horizontal, la autogestión y abogan por la culturización de la política y por acciones plurales directas.

Para identificar el tránsito de las organizaciones a los colectivos juveniles recurrimos a la revisión teórica y metodológica de investigaciones realizadas en Latinoamérica (Valenzuela, 2007; Rodríguez, 2005; Zarzuri, 2005; Serna, 2000 y 1997) y en Colombia (Escobar, 2003; Mendoza, 2003; Arias, 2002) y el contraste teórico nos permite reconocer los puntos de encuentro y divergencia, de manera que se evidencien los avances académicos y empíricos en los ámbitos local, nacional y latinoamericano. Esta revisión se realiza para conocer el estado de la cuestión en Latinoamérica y Colombia y compararla con las investigaciones efectuadas en Medellín sobre organizaciones juveniles, en la modalidad de Diagnóstico Rápido Participativo (DRP). ${ }^{1}$

1 La Subsecretaría de METROJUVENTUD de la Alcaldía de Medellín promueve las organizaciones juveniles locales y su articulación en red; por ello, entre 2006 y 2009, con la estrategia de Presupuesto Participativo 


\section{ORGANIZACIONES Y COLECTIVOS JUVENILES}

Para conocer los trayectos de la participación juvenil en organizaciones y colectivos en principio se recurre a la revisión del contexto latinoamericano, donde se destacan varias investigaciones puntuales para Argentina (Valenzuela, 2007), Chile (Zarzuri, 2005) y México (Serna 2000 y 1997) en contraste con el estudio dirigido por Ernesto Rodríguez sobre Evaluación de capacidades institucionales de la organización juvenil y los movimientos juveniles en América del Sur (marzo de 2005). La consulta y revisión de estas publicaciones resulta posible gracias a las publicaciones especializadas realizadas en la revista JOVENES del Instituto Mexicano de Juventud y la revista Última Déca$d a$ del CIDPA. Además, se consideran las investigaciones realizadas por el Centro de Investigación en Ciencias Sociales (CESC), de Chile, y el Centro Latinoamericano sobre Juventud (CELAJU).

A fin de conocer las diversas formas de participación política juvenil que transitan entre las organizaciones y los colectivos juveniles nos proponemos, en primer lugar, un recorrido por los estudios realizados en Latinoamérica y Colombia, comparándolas con las rutas de participación ya esbozadas en el primer capítulo, donde se enfatiza en la necesidad de diferenciar participación social, participación comunitaria, participación ciudadana y participación política, considerando las siguientes precisiones (las cursivas son nuestras).

- Participación social se refiere a los fenómenos de agrupación de los individuos en organizaciones en el ámbito de la sociedad civil para la defensa de sus intereses sociales. En esta modalidad de participación, los sujetos no se relacionan con el Estado sino con otras instituciones sociales.

- Participación comunitaria se entiende la relación de los ciudadanos con el Estado, quien cumple una función de impulso asisten-

juvenil, se adelantan caracterizaciones de las organizaciones juveniles en Medellín, con énfasis en localidades que diferencian comunas y corregimientos. Esa estrategia de inversión priorizada por los y las jóvenes resalta la importancia de conocer los procesos organizativos juveniles, a través de investigaciones desarrolladas por jóvenes y acogiendo principalmente la metodología de DRP. Gracias a los estudios realizados, presentamos al final de este capítulo un informe consolidado de las organizaciones juveniles en Medellín. 
cial a las acciones vinculadas con asuntos inmediatos que los primeros deben ejecutar.

- Participación ciudadana, por su parte, hace referencia a la intervención de los individuos en actividades públicas, en tanto éstos son portadores de intereses sociales.

- Participación política entendida como la intervención de los ciudadanos a través de los partidos políticos donde contienden por puestos de representación.

En la investigación «Evaluación de las capacidades institucionales de los Movimientos juveniles en la Región Andina y el Mercosur», coordinada por Ernesto Rodríguez (2005), se presenta un balance de las modalidades de participación política en movimientos y organizaciones juveniles, diferenciando cuatro formas de agrupación juvenil y sus niveles de acción social y política. Se trata de:

i) Los movimientos más politizados (organizaciones estudiantiles, partidos políticos): inciden en particular en las dimensiones más estructurales de la sociedad, pero son muy inestables en sus dinámicas particulares y tienen una escasa preocupación efectiva por la dimensión estrictamente juvenil.

ii) Organizaciones que funcionan con lógicas adultas (scouts, pastorales, rurales): poseen una clara vocación de servicio y una importante estabilidad en el tiempo (más allá de los recambios generacionales que se van desplegando paulatinamente en el tiempo), pero cuentan con menos autonomía.

iii) Organizaciones locales (comisiones municipales, barriales): logran mayores y mejores articulaciones interinstitucionales y acceden a más oportunidades y recursos para desplegar sus actividades, aunque caen a menudo en cierto «activismo».

iv) Grupos más informales (en torno a expresiones culturales, pandillas juveniles, etc.): poseen gran autonomía en su funcionamiento, aunque hay muchas diferencias entre ellas (la categoría es muy abarcativa) y —en general - son difíciles de encuadrar en lógicas relacionadas con políticas públicas en general, y de la juventud en particular.

Las tipologías presentadas por Ernesto Rodríguez (2005:9) permiten ver que las organizaciones juveniles evidencian un quiebre entre movimientos sociales y colectivos juveniles. Los primeros responden a 
los contextos políticos de luchas de clase vigentes hasta los años sesenta y setenta; luego, el panorama se transforma y las formas de acción colectiva se renuevan. En ese momento se evidencia el tránsito de la organización a los colectivos juveniles. Se entiende que los movimientos sociales eran fuertemente ideologizados y formalizados, con estructuras rígidas propias de juventudes políticas, movimientos estudiantiles clásicos, partidos obreros. En cambio, los colectivos juveniles actuales han sido caracterizados como más informales, aglutinados por formas horizontales y con «consignas» colectivas más directamente relacionadas con la vida cotidiana (vigencia de derechos sexuales y reproductivos, libertad de expresión a través de diversas manifestaciones culturales, etcétera).

Veremos entonces que los colectivos juveniles se vinculan por la defensa de derechos asociados a aspectos sociales: edad, género, orientación sexual, con dinámicas de agrupación y de acción que se alejan de las estructuras formales de tipo ideológico y partidista. Los intereses y escenarios de los colectivos juveniles se hallan centrados en la cultura, el reconocimiento de las identidades diversas, los derechos humanos, entre otros aspectos.

Esa transformación en las formas de organización juvenil y su vínculo con la participación política evidencia que ahora los jóvenes privilegian participar en «redes informales», construidas para fines concretos e inmediatos, más que a través de organizaciones formales y fuertemente estructuradas. Estas renovadas formas de agrupación juvenil son nombradas por algunos investigadores como «nuevos movimientos sociales». Para Alberto Merlucci (citado por Delgado, 2007), los nuevos movimientos sociales hacen referencia a un conjunto de formas de acción colectiva diferentes de aquéllas basadas en las divisiones entre clases sociales, que en su momento dominaron los escenarios del conflicto social en Europa y Estados Unidos, desde la Revolución industrial hasta después de la Segunda Guerra Mundial.

Ahora los jóvenes privilegian agrupaciones en pro de cambios efectivos - aquí y ahora-, donde los «cuestionamientos» se relacionan con la vida cotidiana. No se trata de cambiar la sociedad para cambiar - después - a las personas, sino de promover cambios en ambas esferas, simultáneamente.

En ese sentido, Raúl Zarzuri Cortés manifiesta:

Los jóvenes asisten a la proliferación y multiplicación de pequeños grupos de «redes existenciales», que resisten o intentan resistir a los emba- 
tes de la globalización y a la uniformidad de estilos de vida. En el fondo, asistimos a la saturación de lo político, y emergen los microgrupos o microsolidaridades; o sea, nuevas forma de ver y de participar, que precisamente vienen a llenar ese vacío de generar matrices discursivas que puedan interpelar a los jóvenes, ya que la juventud se siente conmovida con aquellas cosas que precisamente la "gran política excluye», la cuales caen por los retículos de las grandes organizaciones políticas, lo que lleva a que los jóvenes practiquen una denegación de la política, altamente política (Zarzuri. 2005:8).

Se trata de una inversión de las formas de agrupación juvenil que no pasan por la «política tradicional»y, por ende, la construcción de lo político en jóvenes se vincula con otros ejes, que escapan a las formas tradicionales de configurar o construir lo político.

En palabras de Rossana Reguillo:

La política en los jóvenes pasa por el deseo, la emotividad, la experiencia de un tiempo circular, el privilegio de los significantes sobre los significados, las prácticas arraigadas en el ámbito local que se alimentan incesantemente de elementos de la cultura globalizada [...] cuestiones que posibilitan ver a la política ya no como un sistema rígido de normas, sino como un red variable de creencias, un bricolaje de formas y estilos de vida, estrechamente vinculados a la cultura [...] Es una política con minúscula, que adquiere corporeidad en la práctica cotidiana de los actores, en los intersticios que los poderes no pueden vigilar (Reguillo, 2000:43).

La ruptura en las modalidades de participación política juvenil se puede concebir como el paso de las organizaciones a los colectivos juveniles, considerados éstos cuales formas puntuales y locales de agrupación. Entendemos entonces que la participación política no parece ser un eje articulador de los colectivos juveniles, al presentarse una tensión entre la política y las nuevas formas de agrupación juvenil. Ante esa tensión, Raúl Zarzuri (2005) propone pensar en el tránsito de organizaciones juveniles a colectivos juveniles, considerando las denominaciones de algunos teóricos sobre «nuevos movimientos sociales» (Feixa, Saura y Costa, 2002).

Tal como lo plantean estos autores:

Hablar de experiencias colectivas de participación juvenil nos conduce a plantearnos una pregunta fundamental ¿hasta qué punto podemos considerar a los movimientos juveniles como movimientos sociales? La respuesta a esta interrogante depende de la concepción de movimiento 
social que manejemos, no se debe olvidar que el término Movimiento social, tal y como lo conocemos hoy en día, se comenzó a utilizar a principios del siglo XIX con un sentido específico: designar casi exclusivamente al movimiento obrero; si bien encontramos a lo largo de la historia la presencia de sectores juveniles vinculados a las luchas del movimiento obrero, no podemos hablar propiamente de movimientos sociales juveniles (Feixa y otros, 2002:11).

Los Movimientos Estudiantiles de los años sesenta (Mayo 68) marcaron un giro tanto en la teoría cuanto en la práctica política. Los teóricos de la contracultura anunciaron la emergencia de la juventud como una nueva clase - vanguardia de la sociedad futura-, optando por la revolución cultural más que por la ruptura política. Así, la expresión «Nuevos Movimientos Sociales» (NMS) comienza a usarse para designar determinadas formas de acción colectiva que proliferan a partir de la segunda mitad de los años sesenta, y que resultan difíciles de explicar desde los modelos prevalecientes en este campo. Lo segundo deviene a consecuencia de que son protagonizadas por una variedad de individuos y grupos a los que no cabe situar en posiciones estructurales homogéneas.

Ante la diversidad de expresiones y formas de agrupación juvenil resulta cada vez menos posible caracterizar a los «nuevos movimientos sociales» como una consecuencia de las contradicciones económicas; más bien hay que analizarlos como productos del campo cultural, que afectan la identidad personal, el tiempo y el espacio de la vida cotidiana, la motivación y los patrones de cultura de la acción individual. En cuanto a la forma organizativa, los nuevos movimientos sociales están conformados por grupos difusos y fluidos, situación que tiene que ver con una forma organizativa descentralizada en la que se promueve la toma de decisiones.

El investigador Larreña (citado por Delgado, 2005) asocia los nuevos movimientos juveniles a movimientos de la identidad, y los considera:

Un indicador de cambio en las reivindicaciones de los movimientos sociales, las cuales se desplazan de los factores económicos que las caracterizaban hacia otro tipo de problemas y de intereses más centrados en la cultura, en el reconocimiento de la identidad individual y social, en el medio ambiente, en la justicia, en la promoción de los derechos humanos, en la estructura tradicional de los roles en la familia, en la seguridad colectiva de los ciudadanos, entre otros aspectos. 
Sin embargo, nos vemos enfrentados a un nuevo contexto y, con ello, a otras formas de agrupación, movimientos y protestas protagonizados por jóvenes, lo que nos lleva a modelos de movilización colectiva que presentan algunos rasgos distintivos, tanto respecto a los «viejos» cuanto a los «nuevos» movimientos sociales. Por ello, incluso autores como Feixa hablan de «novísimos» movimientos sociales (Feixa, 2002:17).

\section{DINÁMICAS DE LAS ORGANIZACIONES Y LOS COLECTIVOS JUVENILES}

Las organizaciones juveniles se presentan como una forma de agrupación estructurada que se caracteriza por la visibilidad y visualización concreta de actividades, objetivos, estructura organizativa, procesos regulados de funcionamiento y con un fuerte propósito de proyección social y comunitaria. En general, la organización juvenil pone en evidencia sus niveles de formalización, con intención clara de contar con personería jurídica para obtener una interlocución más válida y legítima con otros actores políticos y sociales.

Según Leslie Serna (2000), la organización juvenil puede contar con dos tipos de orientación: aquéllas promovidas por adultos para jóvenes y las creadas por los mismos jóvenes. En las primeras, la institucionalidad juega un papel fundamental; mientras, en las segundas, la independencia y la autodeterminación son ejes centrales de la organización.

Las organizaciones juveniles presentan una gran diversidad de elementos de cohesión y articulación del grupo, pueden responder a intereses deportivos, culturales, comunitarios, comunicativos; a su vez, resulta común encontrar organizaciones juveniles con diversas formas de articulación: la música, el teatro, la gestión cultural y acción comunitaria. A pesar de los diversos modos de participación juvenil presentes en las organizaciones, es posible afirmar que las integradas a instituciones adultas reproducen identidades legitimadoras de la sociedad civil, que reiteran fuentes de dominación tradicionales. El investigador Jair Vega (2007) las denomina «organizaciones dependientes», al estar inscriptas en formas institucionalizadas y burocráticas de participación que tergiversan la democracia liberal al convertirse en «caparazones vacíos», distantes de estructuras y procesos deliberativos, bajo la consigna de libertad y resistencia civil.

En la relación juventud y participación se presentan renovadas maneras de agrupación juveniles reunidas alrededor de acciones y propuestas estéticas y artísticas de resistencia, que hacen de la música, 
la danza, la comparsa, el graffiti y el esténcil medios de divulgación de la divergencia política, con acciones directas de alto impacto en el espacio público. En palabras de Leslie Serna hablamos de colectivos culturales, al tratarse de:

Pequeños grupos expandidos por todas las ciudades. Dan la impresión de guerrilleros simbólicos cuyo campo de batalla es el espacio urbano; su meta, el control de los recursos culturales; su arma, la comunicación. Los colectivos culturales son la mejor expresión de la diversificación contemporánea de las culturas juveniles. A los chavos bandas se han sumado los sketes, darks, raves, rastas y, desde luego, los punk, entre muchos otros. Son identidades transgresoras, cuya estética anuncia un anhelo de transformación. La música, el lenguaje, la ropa y accesorios, los productos culturales, con rebeldía, voluntad de cambio y, en cierta manera, micropropuestas para un nuevo orden.

La comunicación es la herramienta central de los colectivos. Es impresionante la cantidad de fanzines, revistas, videos, grafitos que se producen e intercambian. La creatividad en su diseño y elaboración asombraría a más de un adulto. Las publicaciones suelen ser irreverentes y contestatarias. No hay propuesta política ni plan, hay sueños e imaginación (Serna, 2000:125).

Los colectivos representan agrupaciones con determinado posicionamiento cultural e, incluso, de política local. Los colectivos tienen una definida y anunciada identidad grupal, implican la presencia de algún consenso básico, y conservan el desapego respecto a las formalidades innecesarias. Su discurso revela de modo prominente el carácter democrático-participativo de los colectivos: todos sus miembros piensan, deciden y actúan; no hay censura, no hay jefes, la representatividad se limita a los que quieren participar; es decir, la participación subordina la representatividad.

Se resaltan las siguientes características (Valenzuela, 2007:39-40):

- Relación con el poder. Los esfuerzos de los colectivos juveniles no se orientan a la conquista del poder a través de la toma del Estado, puesto que se centran en temáticas más cercanas a la cotidianidad y a las luchas sectoriales, concibiendo al «poder» no como algo que se toma, sino más bien asociándolo a la positiva potencia del trabajo colectivo. Los jóvenes de los colectivos conciben el poder ligado al «hacer juntos», a la «actividad común», al «poder hacer»y, en tal sentido, se distancian del «poder-sobre». 
- Autogestión. La forma de financiamiento de las actividades obedece a la autogestión; alternativa a la dependencia económica.

- Culturalización de la política. Tomando prestado el concepto de Reguillo (2003), la culturalización de la política apunta al mirar y hacer política desde la cultura. Es este fenómeno el que se observa en las prácticas de los colectivos juveniles analizados, los que a través de la música, talleres artísticos, festivales, ferias de la cultura, etcétera, transmiten mensajes abiertamente políticos.

- Pluralismo. Los colectivos están conformados por jóvenes con diversas ideas y visiones de la sociedad. Al contrario de las estructuras políticas tradicionales, los colectivos se enriquecen de las diferencias específicas de los jóvenes, otorgándoles a sus expresiones organizativas un sello de tolerancia y democracia.

\section{ORGANIZACIONES JUVENILES EN COLOMBIA}

Los estudios referidos a organizaciones juveniles en Colombia son más bien recientes, si se considera que sólo la sociología y el trabajo social cuentan con líneas de investigación en dicha temática, al preocuparse de los procesos organizativos en ámbitos sociales, populares y comunitarios. En esos espacios, las expresiones y acciones juveniles quedan invisibles o resultan marginales frente a la consideración tradicional de organización, concebida como «una colectividad instituida con miras a unos objetivos definidos, un orden normativo propio, unos rangos de autoridad y unos sistemas de acción coordinados [...]. En ese sentido, la organización social es relevante mientras se constituye a partir de experiencias asociativas de pobladores, dispuestos a la solución de problemas urbanos y necesidades locales como equipamiento social y físico» (Baena y Ruiz, 2004:39).

Si realizamos una diferenciación cronológica de las formas de organización juvenil en Colombia, encontramos que en los años sesenta y setenta los movimientos estudiantiles, los partidos y los movimientos políticos, en especial de izquierda, fueron los escenarios centrales en los cuales la juventud quiso expresarse políticamente. En esa época, los jóvenes adhirieron orgánicamente a asociaciones dirigidas por adultos, aunque el movimiento estudiantil fue el escenario en que lograron mayores niveles de autoconstrucción simbólica y cultural.

La década de los sesenta anunciaba un proceso acelerado de urbanización y concentración poblacional en las ciudades, momento 
cuando empiezan a constatarse las primeras dinámicas sociales propiamente juveniles de tipo estético (rock y literatura) y cuando en las universidades públicas, y aun privadas, germinaba lo que constituiría el movimiento estudiantil como escenario de politización de la juventud. El cambio se hallaba estimulado por el fragor de la revolución cubana, las protestas contra la guerra de Vietnam, el «Mayo del 68», el liderazgo de Camilo Torres Restrepo y el proceso de configuración de la guerrilla colombiana, entre otros fenómenos culturales y políticos de orden nacional y mundial.

La juventud se constituyó en impulso vital de los movimientos de transformación social y política promovidos por adultos disidentes, contradictores del orden impuesto, especialmente opositores a un tipo de subjetividad centrada en el individualismo y a una sociedad hegemónica propulsora de desigualdades. Los jóvenes tomaron en sus manos las banderas del socialismo.

En la década de los 90, importantes segmentos de jóvenes optaron por organizarse en torno a diversos objetivos que contribuyeran, en términos generales, a resistir la espiral de violencia y de guerra producida por el narcotráfico y por la combinación compleja de bandas y milicias descendientes de la guerrilla. En tal escenario, las manifestaciones artísticas, culturales y estéticas aglutinan los intereses de los jóvenes, y el centro de interés y preocupación se desplaza desde las instancias regulares de la cultura dominante a los territorios de la diferenciación y de la pluralidad.

\section{a) Los enfoques disciplinares}

Al referirnos a los enfoques disciplinares, debemos decir que los lugares de reflexión e investigación de las organizaciones juveniles son la sociología y el trabajo social, pues plantean, a su vez, los derroteros y las acciones precisas de las organizaciones sociales; en tanto, los actores sociales buscan reivindicar sus derechos y aportar significativamente a la construcción de ciudad y de ciudadanía democrática.

En ese sentido, Manuel Castells (2001) reconoce tres dimensiones fundamentales a partir de las cuales se dio el desarrollo de las organizaciones sociales:

- La dimensión más reconocida es la que vincula a la organización con las luchas referidas al consumo colectivo; o sea, la defensa de las condiciones de vida en el sentido más amplio: bienes y servi- 
cios, equipamiento urbano (vivienda, servicios públicos, infraestructura...)

- La segunda la constituye la construcción de la identidad social y cultural con base territorial, referida a la comunidad local o barrial, considerada elemento fundamental de relación interindividual y colectiva.

- La tercera es la afirmación de la autonomía política local, que permite reconstruir las formas democráticas del poder y de la administración del Estado basada en la capacidad de gestión de la participación ciudadana y su incidencia en los órganos del Estado.

Desde esas dimensiones, las organizaciones juveniles no tienen relevancia en tanto no cumplan con propósitos referidos al desarrollo local, colectivo y político de forma explícita. Así, pese a la importancia que reviste la constitución de espacios organizativos juveniles en la construcción de vínculos sociales, los estudios son escasos y los desarrollos conceptuales aún incipientes; aunque recientemente se encuentran estudios que valoran las acciones juveniles tendientes a la proyección comunitaria, la participación o el liderazgo, y pongan de presente la multiplicidad de formas de expresión identitaria y movilización juvenil: ecologistas, deportivas, culturales, estudiantiles, artísticas, religiosas, políticas, sociales. Los trabajos adelantados sobre esta temática resultan escasos y poco desarrollados (Colombia Joven, 2001; Mendoza, 2003; Escobar, 2003).

En Bogotá, por ejemplo, el trabajo más reciente sobre las expresiones organizativas de los jóvenes la realiza José Cabrera (2000) Dimensiones simbólicas de la participación juvenil: la experiencia de los grupos comunitarios en Santafé de Bogotá. Para el abordaje de las organizaciones comunitarias, el autor propone tres dimensiones de análisis: La identitaria, la organizativa y la interrelacional. La dimensión identitaria reconoce las estéticas, la necesidad de reconocimiento social y las búsquedas de las organizaciones juveniles investigadas (zona 4 de Bogotá). La segunda dimensión evidencia el sentido que adquiere la organización para los y las jóvenes al convertirse en un espacio de expresión y en lugar vital para compartir experiencias con el grupo de pares. Finalmente, la interrelacional confirma que las organizaciones comunitarias permiten que los y las jóvenes construyan mayores niveles de pertenencia con los ámbitos locales y vayan constituyendo un actor juvenil que se hace visible en el espacio público (citado por Mendoza, 2003:41). 
Resulta urgente capturar la heterogeneidad y la diversidad de formas organizativas juveniles, que considere y contraste las tradicionales con las emergentes, y ubicar cómo se experimenta desde ellas el poder, la autoridad, la formulación de proyecto(s), las formas de gestión, las modalidades de inclusión de sus miembros, las estrategias de «reclutamiento», las interacciones con otras organizaciones en el plano horizontal (otros movimientos sociales) y vertical (con el Estado y las instituciones gubernamentales) $\mathrm{y}$, especialmente, los lenguajes que estas organizaciones expresan como «nuevos» signos de lo político (Reguillo, 2000).

Escobar y Mendoza lo manifiestan así:

...si bien la organización no es la única vía para entender la participación de los y las jóvenes, constituye una entrada relevante por el carácter que lo organizativo juvenil tiene en ese momento sociohistórico. Estamos ante generaciones a las que la institucionalidad les ofrece abiertamente mecanismos para participar en el todo social y «organizarse», es precisamente uno de los más legitimados. Un joven solo o una agrupación juvenil «informal», difícilmente logran interlocutar con la institucionalidad adulta; un «parche», un grupo de amigos de un barrio pueden hacerse visibles en su contexto, pero su participación en los procesos de decisión local tiene más opción si asumen algunas de las lógicas organizativas que los muestren como representativos de lo juvenil de su zona o población (Escobar, 2003:76).

De ese modo, hay un ambiente de preocupación sobre la respuesta de las organizaciones a estos postulados, pues frente a la institucionalidad resultan despolitizadas y apáticas a propuestas políticas o procesos de participación sociales.

La autora mexicana Leslie Serna (2000) plantea una disyuntiva en la relación jóvenes y participación: i) una fuerte pérdida de credibilidad en el Estado como referente nacional y local; ellos hablan de las pocas soluciones que ofrece para la solución de sus necesidades reales. ii) La crisis de los partidos políticos y su escasa influencia como referentes de renovación política; pocos fueron los que describieron los partidos políticos que conocían, y si lo hicieron, estaba relacionada con figuras y acciones y ninguno a sus principios ideológicos.

Frente a la visión de los «jóvenes sin participación», la investigadora Leslie Serna plantea invertir la mirada para visibilizar las organizaciones juveniles que buscan alejarse del mundo adulto en pro de su autonomía. En tales organizaciones se propone y se gestiona 
con un sentido general de autodeterminarse para lograr autonomía: política (grupos de defensa del medio ambiente, derechos humanos, derechos de los pueblos indios) y cultural (colectivos culturales). Ellas buscan recomponer un cierto orden institucional en muy variados grados, a partir de lograr una mayor representación e incidencia de los jóvenes (Serna, 2000:121).

\section{DESCRIPCIÓN DE LAS ORGANIZACIONES Y COLECTIVOS JUVENILES EN MEDELLÍN ${ }^{2}$}

El primer referente formalizado acerca de las organizaciones juveniles de la ciudad se ubica en un estudio realizado por la Red Paisa Joven, en 1995, en el cual se identificaron 570 organizaciones juveniles activas. Después de este estudio, como hito, cabe señalar la última década del siglo XX, dado que en razón del fenómeno del narcotráfico los jóvenes fueron visibilizados como víctimas y victimarios de la violencia social desencadenada. Tal situación confronta a las instituciones y a los propios jóvenes con el lugar que hasta el momento habían ocupado y que en adelante deberían hacerlo en el concierto de la ciudad y de la problemática social que acontecía en ese momento histórico.

En simultáneo con esta coyuntura social, la organización juvenil en la ciudad, en los barrios, en las comunas cobró fuerza por la vía de reivindicar su lugar y su protagonismo social, político y cultural, de modo tal que su presencia social se constituyó en un referente para el Estado, la sociedad civil y las generaciones venideras.

Entre 1990 y 2000 se presentó en la ciudad un apogeo de organizaciones juveniles de diverso carácter: social, religioso, artístico, y programas juveniles de organizaciones gubernamentales y no gubernamentales, que responden a la situación juvenil en la ciudad. A modo de contraparte a estas propuestas de reivindicación y de vida surgieron múltiples bandas armadas conformadas en respuesta a esta situación y al trabajo que desde años atrás se venía gestando en la ciudad con lo juvenil. Se generaron en el municipio diversas propuestas que impul-

2 Esta aparte considera las Caracterizaciones de Organizaciones juveniles en Medellín realizadas a través del Presupuesto Participativo Juvenil y aplicado por comunas (Ver Subsecretaría METROJUVENTUD). También se cuenta con la caracterización de las organizaciones juveniles en corregimientos realizada en convenio por la Universidad de Medellín y Comfenalco Antioquia (libro en prensa). 
saban la organización juvenil: la Oficina de la Juventud, la Mesa de Juventud y las redes juveniles, el Consejo Municipal de Juventud y la Red Paisa Joven. Igualmente, la elaboración de los Planes Zonales de Desarrollo Juvenil, el primer CMJ y la creación de los Clubes Juveniles fueron estrategias para visibilizar a la población juvenil y fomentar sus procesos organizativos. (Márquez, 2005)

En el 2003, El Observatorio de Juventud de Medellín registró que en la ciudad existen 103 grupos juveniles adscritos al sector religioso, 170 organizaciones juveniles (entre grupos, clubes y asociaciones), con variedad de fines (artísticos, deportivos, ecológicos, entre otros), la mayoría de los cuales se ubica en las comunas 2 y 6 , pero no se reportan en este momento clubes juveniles en la comuna 15. También se reconocen, según informes de la entonces denominada Oficina de Juventud, 150 clubes juveniles, cuya mayor presencia se halla en los barrios Popular, Manrique y 12 de Octubre, zonas con tradición y fortaleza en procesos de participación social y organización comunitaria. Tampoco en esta modalidad aparecen reportados clubes juveniles pertenecientes a la comuna 15. En las 58 Mesas Barriales de Convivencia se registró la participación de 463 personas procedentes de 74 organizaciones juveniles de la ciudad, con mayor presencia de las comunas 8, 3, 6 y 13 .

Entre el 2006 y 2007, la Secretaría de Cultura Ciudadana de la Alcaldía de Medellín, a través de la Subsecretaría de METROJUVENTUD y la estrategia de Presupuesto Participativo Juvenil, se adelantan caracterizaciones de las organizaciones juveniles en Medellín, con énfasis en localidades que diferencian comunas y corregimientos. Gracias a esa estrategia de inversión priorizada por los y las jóvenes, se hace resaltar la importancia de conocer los procesos organizativos juveniles a través de investigaciones desarrolladas por jóvenes, donde se acoge principalmente la metodología de DRP. Buena parte de ese ejercicio se realiza en 2007.

Las caracterizaciones consideran que para reconocer y fortalecer la organización y la participación juvenil es fundamental lograr avanzar en un inventario general de la ciudad y tener claridad por comunas y corregimientos sobre «qué hacen, cómo se organizan y en qué espacios participan, para poder orientar mejor las acciones de formación, promoción y apoyo desde la Alcaldía y las organizaciones sociales de la ciudad» (Alcaldía de Medellín. Secretaría de Cultura Ciudadana. Presupuesto Participativo). 
Se cuenta con:

- Las formas de participación en la comuna 16 de Medellín (Belén) (diciembre 2007).

- Diagnóstico rápido participativo de las organizaciones y grupos juveniles de la comuna 2 (Santa Cruz) (diciembre 2007).

- Diagnóstico rápido participativo: Estado de la organización juvenil comuna 15 (Guayabal) (noviembre 2007).

- Caracterización de las organizaciones juveniles de la comuna 6. (San Antonio de Prado) (noviembre 2006).

- Formas de agrupación juvenil en los corregimientos: Altavista, San Cristóbal y Palmitas (junio 2006).

Los estudios plantean la necesidad teórica y práctica de reconocer las diversas agrupaciones juveniles que involucran la participación social, cultural o política, para lograr superar una mirada que sólo reconoce la organización en función de la participación comunitaria; categoría que encierra un gran imaginario de la organización, en cuanto aporte al desarrollo local y la integración sociocultural, propia de las organizaciones popular y comunitaria.

A su vez, las caracterizaciones mencionadas tratan de superar una tendencia muy marcada en la producción investigativa local, que busca caracterizar a los jóvenes en tanto se encuentran organizados. Y esa organización se halla supeditada a dos disyuntivas: una, las organizaciones integradas por jóvenes (promovidas por adultos) y otra, las organizaciones juveniles (promovidas por los jóvenes).

Se trata de una tendencia que abarca incluso las investigaciones latinoamericanas, pues como lo plantea Leslie Serna:

Se reconocen, en principio, dos tipos de organizaciones juveniles, que dan cuenta de composición, origen y propósitos promovidos: una, desde fuera del universo juvenil, que se generan por vínculos ideológicos y financieros con otras instituciones o otros actores de la sociedad civil, y la segunda, como procesos impulsados por los propios jóvenes en respuesta a necesidades o desafíos a la autoridad, las instituciones o la otredad (Serna, 2001:120).

Las caracterizaciones de Medellín buscan superar esa disyuntiva, pero parece ser una dualidad que atrapa las formas de agrupación juvenil, pues se mantienen en la institucionalidad promovida por la Iglesia, la escuela y la acción comunal... Y, de otro lado, emergen las expresio- 
nes y prácticas juveniles de naturalezas artísticas, culturales y comunicacionales entendidas como formas de agrupación juvenil «informales», que desde la cultura redimensionan las formas de participación juvenil, por su capacidad de generar cohesiones y redes de movilización, reivindicación y hasta de ampliación de la diversidad juvenil.

Así lo plantean Arias y Medina:

Es importante reconocer los diversos modos en que la juventud constituye su acción intencionada, a través de organizaciones o grupos de jóvenes que sin estructura orgánica definida acuden a formas expresivas con las que comunican interpretaciones propias de su entorno y proponen otras trayectorias de vida, que pueden concebirse como representaciones de una ciudadanía juvenil en términos políticos, sociales y culturales (2007:8).

Al revisar los procesos organizativos juveniles, las caracterizaciones nos permiten afirmar que para el caso particular de Medellín las asociaciones juveniles «informales» cumplen con el rasgo esencial de ser espontáneas, voluntarias, autónomas y pluralistas (no excluyentes). Y las organizaciones «formales» encuentran un rigor organizativo que mantiene la dificultad de flexibilizar los mecanismos de participación, lo que limita su vinculación a propuestas puntuales y de corto plazo, pues quedan atrapadas en el formalismo propio del trámite burocrático. Además, existen mientras la institucionalidad asegure su permanencia, como en el caso de las organizaciones escolares, eclesiales y comunitarias.

En la relación juventud-organización-participación se reitera el reconocimiento a diversos modos de asumir las acciones y proyecciones de los y las jóvenes, considerando diversas rutas de organización juvenil. Sobresalen en número los grupos artísticos, que asocian la participación exclusivamente con sus procesos y proyectos particulares y locales. Pero la dimensión de su participación no trasciende el horizonte de la práctica estética, creyéndola el único espacio concebido para instalarse en una perspectiva más de ciudad.

Como lo enuncian los investigadores Arias y Medina

Hay punkeros que sólo quieren tocar música, chiquitecas que sólo quieren bailar, Mil Espadas simular batallas medievales [...] Pero matizando la afirmación es claro que los grupos artísticos plantean que participar consiste en poder realizar el personal y grupal, ya sea porque hay escepticismos e incredulidad respecto a una participación efectiva y real en la 
ciudad o porque su experiencia grupal ha consistido en enfrentar situaciones de exclusión y persecución por proponer rupturas y transgresiones a un orden social constituido o, a su vez, porque consideran que desde el proyecto artístico se contribuye de diferentes maneras al desarrollo social, al conocimiento y formación de otras personas (Arias y Medina, 2007:13-14).

En general, las caracterizaciones reconocen la diversidad juvenil agrupada alrededor de propuestas culturales, artísticas, musicales, recreodeportivas, cooperativas, de emprendimiento, comunitarias y religiosas, con gran porcentaje de grupos juveniles reunidos alrededor del arte y la cultura. Los diagnósticos de las organizaciones juveniles eligen como ruta inicial identificarlas y caracterizarlas a partir de los ejes temáticos que las reúnen, considerando, así, temas y acciones de articulación. Hay grupos que responden a: cultura, deporte y recreación, comunitario, religioso, emprendimiento, educativo, ambiental, comunicación.

En el cuadro siguiente es posible ver el número de organizaciones y su asociación a ejes temáticos, discriminados por comunas.

\section{CUADRO COMPARATIVO DE LAS ORGANIZACIONES JUVENILES EN MEDELLÍN}

\begin{tabular}{|l|c|c|c|c|c|c|c|c|}
\hline Lugar / Tipo & Comuna 2 & Comuna 6 & $\begin{array}{c}\text { Comuna } \\
16\end{array}$ & $\begin{array}{c}\text { Comuna } \\
15\end{array}$ & $\begin{array}{c}\text { Correg. } \\
\text { Prado }\end{array}$ & $\begin{array}{c}\text { Correg. } \\
\text { Altavista }\end{array}$ & $\begin{array}{c}\text { San } \\
\text { Cristóbal }\end{array}$ & Palmitas \\
\hline Cultura & 11 & 35 & 60 & 17 & 10 & 4 & 13 & 1 \\
\hline $\begin{array}{l}\text { Deporte } \\
\text { y recreación }\end{array}$ & 8 & 16 & 9 & 3 & 5 & 3 & 3 & 1 \\
\hline Comunitario & 5 & & 15 & 4 & 3 & & & \\
\hline Religioso & 2 & & 6 & 3 & 2 & 1 & & \\
\hline Emprendimiento & 2 & 1 & 4 & & & & & \\
\hline Educativo & & 3 & & & & & 3 & 1 \\
\hline Ambiental & & 2 & & & 1 & & 3 & \\
\hline Comunicación & 1 & 1 & & & 1 & & & \\
\hline Todos los tipos & & & & & & & 6 & \\
\hline Total & $\mathbf{2 9}$ & $\mathbf{5 8}$ & $\mathbf{9 4}$ & $\mathbf{2 7}$ & $\mathbf{2 3}$ & $\mathbf{8}$ & $\mathbf{2 8}$ & $\mathbf{3}$ \\
\hline
\end{tabular}

En las caracterizaciones realizadas en Medellín entre 2006 y 2007 se reportan 271 organizaciones juveniles con una distribución porcentual por ejes temáticos bien diversa, donde sobresale el eje articulador cultural. 
De organizaciones a colectivos juveniles

CUADRO DE DISTRIBUCIÓN PORCENTUAL DE ORGANIZACIONES JUVENILES EN MEDELLÍN

\begin{tabular}{|l|c|c|}
\hline Tipo & Porcentaje & Frecuencia \\
\hline Cultura & 55.5 & 151 \\
\hline Deporte y recreación & 17.7 & 48 \\
\hline Comunitario & 9.96 & 27 \\
\hline Religioso & 5.9 & 16 \\
\hline Emprendimiento & 3.58 & 7 \\
\hline Educativo & 3.58 & 7 \\
\hline Ambiental & 2.21 & 6 \\
\hline Comunicación & 1.1 & 3 \\
\hline Todos los tipos & 2.21 & 6 \\
\hline Total & & $\mathbf{2 7 1}$ \\
\hline
\end{tabular}

\section{CONCLUSIONES}

El rastreo de antecedentes teóricos y un primer acercamiento a las formas de participación política juvenil a partir del diálogo con los desarrollos investigativos en Latinoamérica y Colombia, nos permiten esgrimir las siguientes conclusiones.

i) Cualquier indagación seria acerca de la participación política juvenil compromete decididamente la pregunta por la condición juvenil en cada momento histórico y en cada contexto social. Esta consideración aparece producto del consenso entre los investigadores del tema de participación juvenil, y se sustenta en la idea de que en muchas ocasiones juzgamos las actitudes o las actuaciones juveniles a partir de una imagen cargada de añoranza de lo que significaba ser joven en otro momento histórico.

ii) En los y las jóvenes los referentes que los congregan están más cerca del arte, la música, la cultura, el deporte y, en general, del universo sensible que de los «grandes ideales de transformación social». Estos referentes no sólo operan como ejes medulares en la construcción de la identidad juvenil - lo que ya es un hecho político-, sino que, a nuestro entender, presentan una dimensión política en distintos sentidos: el primero, porque apuntan a la visibilidad del sujeto joven y la búsqueda de reconocimiento y legitimación social de sus prácticas; el segundo, porque entran en la escena del «mercado político» para lograr que sus proyectos sean considerados en los presupuestos oficiales, y el tercero, porque toman distancia o incluso se convierten en 
grandes cuestionadores (desde la disidencia o la resistencia) de las prácticas políticas hegemónicas.

iii) Los jóvenes son más sensibles que cualquier otro grupo etario a los discursos y a las prácticas que abogan por la diversidad, la inclusión, el cuidado del medio ambiente y los derechos humanos; tal vez esta sea la razón que explique la acogida de ciertos proyectos políticos que acuden a estos referentes.

iv) Los y las jóvenes son más proclives a luchar por las «pequeñas causas» y por los asuntos cercanos a su cotidianidad, que a hacerlo por proyectos o por ideales de largo plazo. Esta condición puede encontrar su explicación en el carácter efímero, flexible y discontinuo que exhiben las organizaciones juveniles.

En coherencia con las formas de participación política presentadas en el presente artículo, es pertinente asumir una noción de participación constituida no sólo por los modos legitimados de participar (organizaciones juveniles), sino por lo que los y las jóvenes en sus formas de agrupación consideran (colectivos juveniles).

De aquí que se debe profundizar en:

i) La relación de los jóvenes con los modos legitimados de participar, entendiendo esto no sólo como las instituciones clásicas (por ejemplo, partidos políticos), sino también con los modos en que se considera «adecuado» participar en ellos (por ejemplo, acuerdos de convivencia escolar).

ii) Las prácticas de participación que los y las jóvenes consideran como tales (a saber, marchas de protesta, tomas de espacio público, conciertos, conmemoraciones sociales y culturales, acciones directas).

iii) Los colectivos juveniles asociados a focos críticos de la sociedad (ley del aborto-clínica de la mujer; desconectados de servicios públicos, seguridad ciudadana y conflicto armado en las comunas).

iv) Los modos de participar que los y las jóvenes crean o reconstruyen en la vida cotidiana, se destacan las escuelas de hip hop, los grupos artísticos, los colectivos de mujeres contra las violencias y agresiones al cuerpo de la mujer.

MEDELLÍN (COLOMBIA), ABRIL 2010

RECIBIDO: ABRIL 2010

ACEPTADO: JUNIO 2010 


\section{REFERENCIAS BIBLIOGRÁFICAS}

AlCALDÍA DE MEDELlíN (2006): Caracterización de las organizaciones juveniles. Comuna seis. Medellín: Secretaria de Cultura ciudadana, Subsecretaría de METROJUVENTUD y Corporación Picacho con Futuro.

ARIAS OROZCO, EDGAR (2002): «La juventud en el reencuentro de lo público. Posiciones y dilemas» JOVENES, Revista de estudios Sobre juventud, Vol. 6, $\mathrm{N}^{\mathrm{o}} 16$. México: IMJ.

ARIAS OROZCO, EDGAR y DAVID MEDINA HOLGUÍN (2007): Las formas de participación juvenil en la comuna 16 de Medellín. Medellín: Instituto Popular de Capacitación, Secretaría de Cultura Ciudadana (inédito).

BAENA OCAMPO, MARÍA EMILIA y ZILIA DAISY RUIZ GUATAQUI (2004): Organización y participación social y comunitaria en Colombia 1991-2001. Bogotá: Fundación Universitaria Monserrate.

BERRÍ LONDOÑO, SANDRA; WALTER DUQUE PUERTA y JUAN BERRÍO (2007): Diagnóstico rápido participativo en las organizaciones y grupos juveniles de la comuna 2 (Santa Cruz). Medellín: Grupo investigación Sinergía, Secretaría de Cultura Ciudadana (sin publicar).

CABRERA, J. (1998): Dimensiones simbólicas de la participación juvenil: la experiencia de los grupos comunitarios en Santa Fe de Bogotá. Bogotá: Tercer Mundo Editores.

DELGADO, R. (2007): «Los marcos de acción colectiva y sus implicaciones culturales en la construcción de ciudadanías». Revista Universitas Humanistica $\mathrm{N}^{\circ} 64$.

(2005): «Análisis de los marcos de acción colectiva en organizaciones sociales de mujeres, jóvenes y trabajadores». Tesis doctorado en ciencias sociales, niñez y juventud. Manizales: Universidad de Manizales y CINDE.

Escobar, Manuel; Nidya Mendoza, M. Cuertas y G. Muriel (2003): ¿De jóvenes? Una mirada a las organizaciones juveniles y las vivencias de género en la escuela. Bogotá: Fundación Antonio Restrepo Barco y Círculo de Lectura Alternativa.

FeIXA, C.; C. COSTA y J. SAURA (2002): «De jóvenes, movimientos y sociedades». En CARLES FEIXA y otros (editores): Movimientos juveniles: de la globalización a la antiglobalización. Barcelona: Ariel Social.

MÁRQUEZ, FUlVIA (2005): «Organizaciones y movimientos juveniles en dos ciudades de Colombia: Bogotá, Medellín». En ERNESTO RODRÍGUEZ: «Evaluación de capacidades institucionales de la or- 
ganización juvenil y los movimientos juveniles en América del Sur». Disponible en: www.urbared.ungs.edu.ar.

MeluCCI, A. (1999): Acción colectiva, vida cotidiana y democracia. México: El Colegio de México.

MENDOZA, N. (2003): «Una aproximación a la discusión sobre culturas y organizaciones juveniles». Revista Facultad de Humanidades $\mathrm{N}^{\mathrm{0}} 18$. Bogotá: Universidad Pedagógica Nacional.

PÉREZ ISLAS, JOSÉ ANTONIO (2006): «Trazos para un mapa de la investigación sobre juventud en América Latina». Papers $\mathrm{N}^{0} 79$. Barcelona: UAB.

REguillo, Rossana (2000): Emergencia de las culturas juveniles. Estrategias del desencanto. Buenos Aires: Norma.

RODRÍGUEZ, ERNESTO (2005): «Evaluación de capacidades institucionales de la organización juvenil y los movimientos juveniles en América del Sur». Disponible en: www.urbared.ungs.edu.ar.

RODRÍGUEZ, SANDRA; MÓNICA MORENO y PATRICIA TEJADA (2006): «La agrupación juvenil en el contexto rural de Medellín y su aporte a la constitución del sujeto joven en actor social (corregimientos de Altavista, San Cristóbal y San Sebastián de Palmitas)». Trabajo de grado en trabajo social. Medellín: Facultad de Ciencias Sociales y Humanas, Universidad de Antioquia.

SERNA, LESLIE (2000): «Las organizaciones juveniles. De los movimientos sociales a la autogestión». Jóvenes, Vol. 4, №11. México: IMJ.

VALENZUELA ARCE, JOSÉ MANUEL (2008): «Identidades y agrupamientos juveniles». En ÁNGELA GARCÉS MONTOYA: Investigación en comunicación: vigencia y prospectiva. Medellín: Sello Editorial Universidad de Medellín.

VALENZUELA, C. (2007): «Colectivos juveniles: inmadurez política o afirmación de otras políticas posibles». Última Década $\mathrm{N}^{\circ} 26$. Valparaíso: Ediciones CIDPA.

VEGA, M. J. (2007): «La construcción de sujetos. De la sociedad civil a la resistencia comunal». Revista Memorias 7. Bogotá: Uninorte.

— y K. EsCALANTE (S/F): «Organizaciones juveniles ¿espacios de formación ciudadana?». Revista Signo y Pensamiento No51.

ZAPATA, C. (2004): «Organizaciones juveniles. Herramientas para su consolidación (Manual)». Medellín: Corporación Paisajoven, GTZ y Escuela de Animación Juvenil.

ZARZURI, R. (2005): «Jóvenes, participación y movimientos sociales: hacia la construcción de nuevas formas de participación juvenil». Santiago: Centro de Estudios Socioculturales (CESC). 